Article

\title{
Industrial Symbiosis Dynamics, a Strategy to Accomplish Complex Analysis: The Dunkirk Case Study
}

\author{
Manuel E. Morales 1,2,3,*(D) and Arnaud Diemer 1,3 (D) \\ 1 CERDI, Université Clermont Auvergne, 26 Avenue Léon Blum, 63000 Clermont-Ferrand, France; \\ arnaud.diemer@uca.fr \\ 2 Industrial Bioeconomy Chair, NEOMA Business School (campus Reims), 59 Rue Pierre Taittinger, \\ 51100 Reims, France \\ 3 Jean Monnet Excellence Center on Sustainability (ERASME), Campus universitaire des Cézeaux-2, \\ avenue Blaise Pascal, 63178 Aubière, France \\ * Correspondence: manuel.morales@neoma-bs.fr
}

Received: 27 January 2019; Accepted: 29 March 2019; Published: 3 April 2019

\begin{abstract}
Industrial symbiosis (IS) is presented as an inter-firm organizational strategy with the aim of social innovation that targets material and energy flow optimization but also structural sustainability. In this paper, we present geographical proximity as the theoretical framework used to analyse industrial symbiosis through a methodology based on System Dynamics and the underpinning use of Causal Loop Diagrams, aiming to identify the main drivers and hindrances that reinforce or regulate the industrial symbiosis's sustainability. The understanding of industrial symbiosis is embedded in a theoretical framework that conceptualizes industry as a complex ecosystem in which proximity analysis and stakeholder theory are determinant, giving this methodology a comparative advantage over descriptive statistical forecasting, because it is able to integrate social causal rationality when forecasting attractiveness in a region or individual firm's potential. A successful industrial symbiosis lasts only if it is able to address collective action problems. The stakeholders' influence then becomes essential to the complex understanding of this institution, because by shaping individual behaviour in a social context, industrial symbiosis provides a degree of coordination and cooperation in order to overcome social dilemmas for actors who cannot achieve their own goals alone. The proposed narrative encourages us to draw up scenarios, integrating variables from different motivational value dimensions: efficiency, resilience, cooperation and proximity in the industrial symbiosis. We use the Dunkirk case study to explain the role of geographical systems analysis, identifying loops that reinforce or regulate the sustainability of industrial symbiosis and identifying three leverage points: "Training, workshop and education programs for managers and directors," "Industrial symbiosis governance" and "Agreements in waste regulation conflicts." The social dynamics aims for the consolidation of the network, through stakeholder interaction and explains the local success and failure of every industrial symbiosis through a system dynamics analysis.
\end{abstract}

Keywords: causal loop diagrams; Dunkirk; industrial symbiosis; complex network analysis; system dynamics

\section{Introduction}

In ecology, the concept of symbiosis describes a closed and often long-term interaction between two or more different biological species. This long-term association may, but does not necessarily, benefit both participants. Symbiotic relationships take place naturally in an ecosystem (different communities of living organisms in association with inorganic environmental components). 
Since 1989, academic literature has shed light on the fact that industry bears a resemblance to natural ecosystems [1], thus closing loops in the industrial socio-ecosystem means the integration of cascading uses, by-product synergies, pooling services and consolidated waste management in an effort of reconciliation with natural ecosystems, even though there are obvious differences from natural ecosystems [2-4]. In recent years, there has been a small but compelling set of studies into the role of Industrial symbiosis stakeholders, such as corporations, SMEs, business associations, anchor tenants and governmental agencies, which has provided enough evidence to recognize the advantages of industrial symbiosis integration in a social ecological dimension [5-9]. Although many studies have focused on industrial symbiosis (IS), most of them focus only on eco-efficiency [10], performance assessments [11] and technical exchange potential using chemical engineering [12]. From the best of our knowledge no significant study has been made into the spatial proximity analysis in the industrial ecosystems. Therefore, the authors accept the challenge to operationalize a systemic approach of social ecological dimension in the industrial symbiosis, through the engagement of applied, social and business management sciences to cope with the spatial proximity analysis of an industrial ecosystem $[13,14]$. Thus, industrial symbiosis is built towards a common understanding of system dynamics governance in the industrial network, analysed from a broader geographical perspective [15-17].

In this paper, we define industrial symbiosis (IS) as an organizational strategy, which is a sub-field of industrial ecology, considering firms as organized organisms. This metaphor proposes a social innovation where industry entails a semi-closed ecosystem in which material and energy flows should be reincorporated in the system by a circular logic. However, it does not mean that inter-firm actions do not concern individual firms. On the contrary, individual firms must integrate IE in the individual project of their company to allow communication and interdependency as members of the system. Thus, we think of industrial symbiosis as a social innovation strategy, based on the ability to transform global society into one that makes better use of materials. In doing this, we are assuming that social innovations in industry could be triggered by metaphors, which make us think out of the box. In that sense, we are going beyond the definition proposed by Chertow [18], who highlights the technical and biophysical aspects. We are convinced that the human dimension is essential for the understanding of industrial symbiosis as a social process, based on ecological, political, cultural and economic aspects. Although Industrial ecology already claims that the social dimension integration improves the theoretical conceptualization of industrial ecosystems dynamics as evidenced by the French school studies on Territorial industrial ecology [19] then simply Territorial ecology [20]. Indeed, this paper aims to contribute with the discussion about the advantages of using geographical systems dynamic approach to embed complexity in the social analysis of industrial symbiosis, [21], enabling a vision beyond firms' individual actions in the search for eco-efficiency.

\subsection{Industrial Symbiosis}

Inspired by the previous iconic studies of industrial symbiosis, we identify two main drivers in the analytical process of industrial symbiosis, as mechanisms that steer the sustainable transition of industry. First, the internal firms' production assessment looking for the economic viability window in the intersection between costs reduction coming from efficiency [22] and the valorisation of by-product improving the technical and economic productivity resulting from the cooperative synergies. Where any disruption or reduction in economic benefits may be sufficient to interrupt the symbiotic flow or, in the worst case, force the departure of a firm from the network [8]. The second driver concerns the broader social sphere aiming to understand and develop the stakeholder coordination within the industrial symbiosis. It is within this second mechanism that we can take advantage of a comparative analysis of the geographical proximity issue [16] in industrial symbiosis.

The current debate highlights the circular economy (CE) addressed in our conceptual framework, which proposes to derive strategies for a shift from a linear to a circular industrial structure $[14,15,23]$. The circular economy is understood in this paper as the extension of value and utility of product, 
therefore production and consumption wastes are used as secondary resources, providing solutions and co-benefits to a range of economic and environmental issues [4,23]. There are four sources of value creation for the circular economy identified in the literature: 1 . The power of the inner circles (the long-lasting durability of products and services), 2. The power of circling longer (the available options of refurbishing, remanufacturing, repairing and reuse of a product or material), 3. The power of cascade use (to diversify reuse along the value chain), 4 . The power of pure inputs (biodegradability, uncontaminated materials and the efficiency of collection and redistribution). Looking at industrial symbiosis as an organizational strategy in the quest of social innovation, we take it to be embedded in the Industrial Ecology field, because it is interested in inter-firm relationships, mainly based on cooperation, highlighting the relationship with the biosphere and using ecological ecosystem dynamics as a metaphor. When evoking industrial symbiosis in the paper, we consider it as one of the axes of circular economy, an axe that focus their efforts in the inter-firm relationship strategies, therefore we can assume that industrial symbiosis puts into practice some circular economy principles. However, despite the growing interest in the industrial symbiosis examples the question of how these circular principles work in practice remains unanswered. More discussion about the biophysical and social influence of stakeholders in the industrial ecosystem is required. Which stakeholders? Which motivations? Which values govern the system's structure?

\subsection{Dunkirk, Industrial Ecosystem Analysis}

The aim of this study, based on results obtained in Dunkirk, is to test the territorial embeddedness of the industrial symbiosis, considered as a social innovative strategy, looking deeper into the systemic proximity understanding of this socio ecological dynamic. To measure geographical proximity, defined as space and relationship distance [24], it seems to be essential to assume that conditions other than the by-product exchange define the geographical location, because by definition, the by-product production firms are multifunctional. Multifunctional firms have functions other than by-product exchange, which usually plays an ancillary role. Therefore, the by-product exchange perspective does not influence a priori their location in the territory, establishing a geographical proximity between production and consumption, which is different from monofunctional production [24]. In the multifunctional firms the by-product synergies depend on primary production processes, leading to a direct relationship in which the greater the final production, the more by-products are generated. Thus, a feedback loop is identified in the production side, since the higher the efficiency in reducing waste, the lower the number of by-products available to be shared. The stakeholder relationship network has already been considered in the literature [3,25] but not through a geographical systems dynamic perspective, which would allow us to better understand the mechanisms, motivations and values in the industrial symbiosis for the sake of sustainability, understood in this study simply as the time endurance of this institutional cooperation mechanism.

The Dunkirk case study provides an excellent base for investigation in a developed country, with an existing and available academic literature about the territorial embeddedness of this industrial symbiosis [12,15-17,24,26-29]. Dunkirk encompasses some features that also seem to facilitate the connections between stakeholders and the collaboration in the network, such as the seaport location and the facilitator role played by the local public authority.

The method for evaluating territorial embeddedness in the industrial symbiosis, underlines the key drivers for each stakeholder's behavioural patterns [30], triggering the systems dynamic approach through a Causal Loop Diagram (CLD), with a coherent narrative string to demonstrate if in the Dunkirk industrial symbiosis territories influence and are influenced by, the industrial system. We analyse the interactive behaviour, cooperation, institutional productive capacity, organizational strategies and by-product flow exchanges, which allow us to understand the qualitative nature of such interdependences. Through this study, we provide relevant insights to answer, what are the key drivers that we need to influence to guarantee the essential functions in the industrial symbiosis? The geographical proximity methodology utilized contributes to the complex understanding of social 
industrial ecosystems, disentangling human motivational causality. In this study, we frame the Dunkirk IS's motivational causality, identified as the economic/political drivers related to the industrial ecosystem structure, the conflicts of interest, game theory, learning process; institutional pathways and idiosyncrasy belong to this social process.

Figure 1, illustrates how the geographical system dynamics approach takes place in the industrial symbiosis, utilizing a common theoretical ground that encompass complexity theory, stakeholders and ecosystems theory, including analytical tools that allow the internalization of complexity in the business and public policies decision-making process. In trying to get a better understanding of the industrial system, an over-simplification of structure would miss some of the properties of the system, because the system's complexity cannot be ignored. In addition, when the ecosystem metaphor is applied to industrial systems, we demonstrate the analytical benefits for the understanding of industrial symbiosis. The industrial ecosystem theory gives room to incorporate complexity into the diversity of industrial stakeholders, supplying them with tools to manage the conflict between different and sometimes contradictory values and interests $[24,26,27]$.

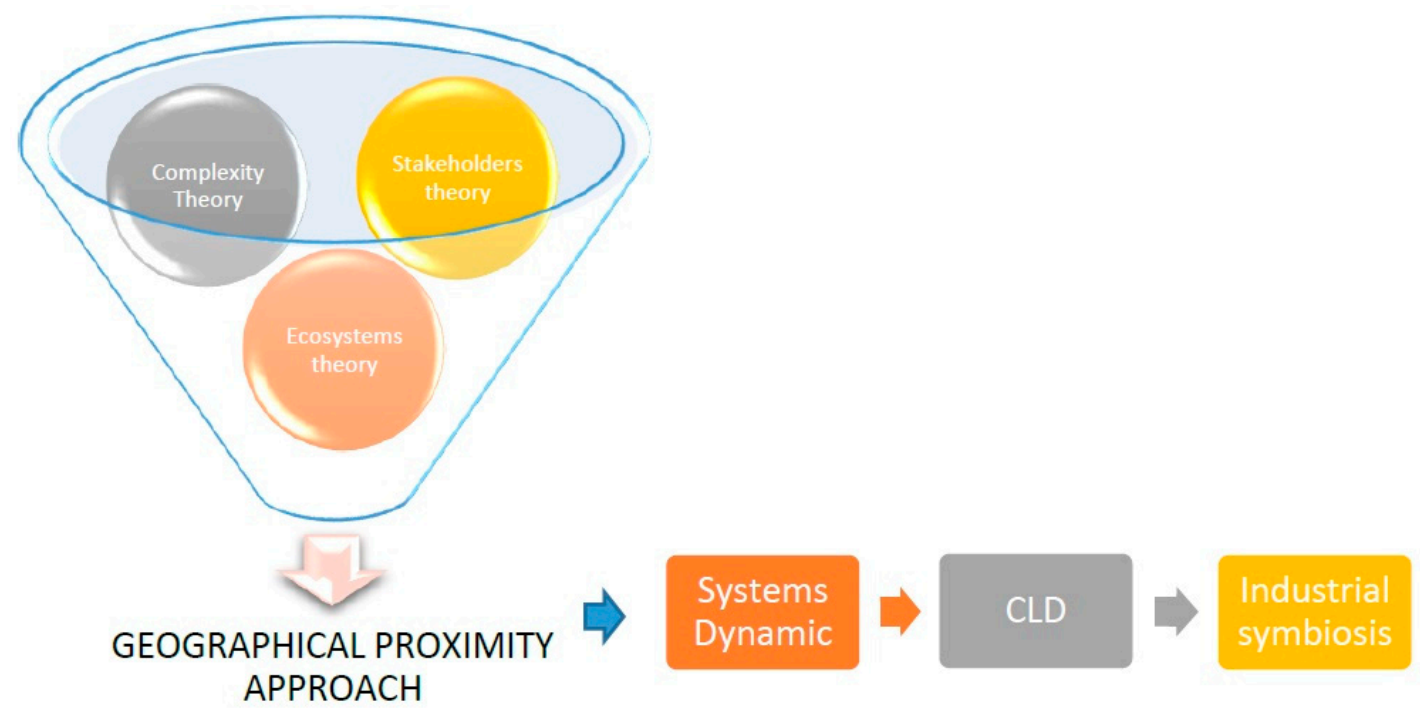

Figure 1. Steps in the geographic system dynamics analysis for industrial symbiosis.

This paper has five sections: In Section 2 we define the theoretical framework for our analysis. Industrial symbiosis is embedded in complexity theory, economic geography theory and ecosystems theory. In Section 3, we introduce system dynamics as a methodology to identify the drivers and leverage points of the industrial symbiosis. The results of the study are analysed using Causal Loop Diagrams (CLD). In Section 4, we discuss the geographical proximity of the Dunkirk industrial symbiosis analysis. Finally, we end the paper with concluding remarks.

\section{Theoretical Framework}

We set the industrial symbiosis understanding on the geographic system dynamics approach for three reasons. First, the approach allows the identification of complex dependence relationships along with the biophysical exchanges accountancy in the industrial network. Based on the recognition of complexity in social industrial ecosystems this paper proposes system dynamics methodology, as a tool to cope with complex adaptive changes [31] in the system, with the ability to produce better long-term scenarios. Second, we argue that geographic economy has explanatory mechanisms for social qualitative analysis, thus industrial symbiosis as the most evolved experience of territorial cooperation between stakeholders, encompasses a profitable arena to get a better understanding of social industrial ecosystems. Last but not least, we use ecosystem theory as a mechanism to approach 
the system's complexity through the analysis of positive and negative behavioural patterns, a structural analysis that provides a systemic answer to the way actors influence the ecosystem's dynamic.

\subsection{Complexity Theory as an Approach to Study the Industrial Symbiosis}

Edgar Morin [32,33] has contributed to the construction of the theory of complexity, even if he does not give a definition; he provides food for thoughts regarding the internalization of complexity. Complexity entails a network of concurrent heterogeneous components, which raises the paradox of unity and diversity, encompassing a chain of events, actions, interactions, feedback, decisions and dangers, shaping our biophysical world. Indeed, we need mechanisms to govern complexity in the research for control over entropic phenomena, to reduce uncertainty and to provide certainty to the unforeseen [34]. Complexity seeks to articulate disciplines that were previously disconnected, not because it seeks to gather all knowledge but because complexity implies the recognition of uncertainty, coping with the tension between the aspiration for unified knowledge and the recognition of knowledge gaps.

Complex thinking [34] highlights two characteristics: 1 . the whole cannot be reduced to the sum of its parts, 2. the system is an ambiguous concept with blurred boundaries. Complexity introduces the idea of balance/instability dualism, which suggests that there is an imbalance in the flows from the environment and without these flows, an organizational disturbance could trigger the degradation of the system. The idea of an open system, out of equilibrium, moving towards a stabilized dynamism could shed light into the environmental context, engaging complexity in ecosystem theory.

From the beginning of the 21st century, the complex adaptive theory has gained interest in the socio-ecological dimension $[3,35]$, because it has helped to improve the understanding of complex socioeconomic systems, which can be defined as a heterogeneous set of actors that interact with the objective of creating new knowledge, as well as changing the organizational structure. System dynamics appears to be a suitable methodology with the required structure to deal with complexity through the ability to identify causality in processes and track the feedback within the structures. System dynamics is able to identify potential radical changes in complex systems coming as small individual changes, whereas linear or statistical models have a tendency to underestimate or miss this information, because the complex system loses reliability when disaggregated.

\subsection{Economic Geography Theory as an Approach to Study Industrial Symbiosis}

Economic geography, defined as the coordinated effort to optimize territorial, economic and political resources, is fundamental to the understanding of a functional industrial symbiosis structure; therefore, geographic proximity becomes a relevant variable to steer social ecosystem analysis in industry. The dynamic evolution of the industrial network, evolving in a complex environment, does not allow the firms involved in by-product exchanges to calculate their optimal geographical localization for suppliers and consumers by traditional linear methods. New methodologies need to be tried in the field of geographical economy, analytical tools hanging on complexity in geographic proximity decision making between producers, consumers and institutions. The dynamic geographical approach encompasses two different complementary dimensions of proximity: geographical proximity defined by distance and relationship proximity, an organizational/institutional proximity, which refers to the interwoven network of relationships beyond the physical space [24].

The geographic economy literature has influenced industrial symbiosis analysis [7], offering possibilities for thinking about complexity. Some examples of this contribution are found in the industrial symbiosis academic literature: by-product synergies, waste management and recycling and the geographically oriented stakeholder analyses embedded in socio-material structures.

A relevant critique of geographic economy considers that geographical proximity between actors is not enough to explain the exchanges and the benefit obtained from industrial symbiosis. The theoretical framework of proximity proposes two different visions: organizational proximity and institutional proximity [24]. Organizational proximity "links actors involved, depending on their 
individual ability to interact and to coordinate activities" whereas institutional proximity "relies on the stakeholders' commitment to a common space of representations, guidelines and rules of collective behaviour." This paper provides an available mechanism to conciliate plurality in the governance of industrial symbiosis [17]. Local governance lays down three main principles to steer industrial symbiosis: 1 . Contradictory interests in explaining the dynamics of governance structures, 2 . The role of geographic dimension to build up coordination mechanisms, 3 . The recognition of contradictory trade-offs values: competition/coordination, global/local, efficiency/resilience, autonomy/authority, which results in processes of hybridization of institutional representations [36]

We operationalize the geographic proximity framework using the method developed by G. Bridge et al., in References $[15,37]$ who provide a detailed conceptualization of six different socio-geographical dimensions of industrial ecosystems: (i) location, (ii) landscape, (iii) territoriality, (iv) scaling, (v) spatial differentiation and uneven development, (vi) spatial embeddedness and path dependency. These are shown in Table 1. The six geographical dimensions help in the analysis of different territorial strategies, assessing the impact of different variable compositions (location, landscape, territoriality, scale, etc.) in the structures.

Table 1. Geographical proximity grid to operationalize industrial symbiosis (IS).

\begin{tabular}{|c|c|c|}
\hline Dimension & Concept & Example \\
\hline Location & $\begin{array}{l}\text { Refers to the absolute and relative } \\
\text { proximity. Due to their transformative } \\
\text { character, socio-technical innovations } \\
\text { change the location of social and material } \\
\text { system entities. }\end{array}$ & $\begin{array}{l}\text { Fossil energies in transport systems in the 19th } \\
\text { century, increased relative proximity between cities } \\
\text { with access to railway but on the other hand, } \\
\text { reduced the relative proximity between cities and } \\
\text { rural without access to the railway. }\end{array}$ \\
\hline Landscape & $\begin{array}{l}\text { Refers how the analyses of socio-technical } \\
\text { innovations affect and transform land. }\end{array}$ & $\begin{array}{l}\text { Wind turbines and solar panel constructions; need } \\
\text { to emphasize that they bring place-attached } \\
\text { emotions and social representations. }\end{array}$ \\
\hline Territoriality & $\begin{array}{l}\text { Socio-technical systems are spatially } \\
\text { determined, encompassing the exertion of } \\
\text { power through place-, space- and } \\
\text { scale-related governance structures. Three } \\
\text { dimensions of territoriality can be } \\
\text { identified: contiguity, connectivity } \\
\text { and centralization. }\end{array}$ & $\begin{array}{l}\text { Contiguity describes geographical density. that is, } \\
\text { transnational energy grids have low contiguity, } \\
\text { whereas industrial symbiosis entails high } \\
\text { contiguity. Connectivity refers to the points of } \\
\text { connection within a system. Centralization refers to } \\
\text { the socio-spatial governance distribution degree, } \\
\text { that is, a gas pipeline has few connection points } \\
\text { (low connectivity), together with few decision } \\
\text { points (high centralization). }\end{array}$ \\
\hline Scaling & $\begin{array}{l}\text { Instrumental variable shedding light on } \\
\text { the reconfiguration capacity of } \\
\text { socio-technical innovations in terms of } \\
\text { who is affected by and who benefits from, } \\
\text { a given strategy. }\end{array}$ & $\begin{array}{l}\text { According to their interests, some actors aim to } \\
\text { foster local resource cycles through industrial } \\
\text { symbiosis, while others might seek to implement } \\
\text { (supra-)national recycling systems. }\end{array}$ \\
\hline $\begin{array}{l}\text { Spatial differentiation and } \\
\text { uneven development }\end{array}$ & $\begin{array}{l}\text { Refers to the differences between places, } \\
\text { defining how the location and landscape } \\
\text { produce intra- and inter-systemic spatial } \\
\text { structures and so winners and losers and } \\
\text { facilitate or hamper fundamental } \\
\text { socio-technical change. }\end{array}$ & $\begin{array}{l}\text { Socio-technical innovations based on common } \\
\text { regulations and standards might promote regional } \\
\text { convergence, although they might lead to spatial } \\
\text { differentiation resulting in uneven } \\
\text { regional development. }\end{array}$ \\
\hline $\begin{array}{l}\text { Spatial embeddedness and } \\
\text { path dependency }\end{array}$ & $\begin{array}{l}\text { Refers to capital and institutions such as } \\
\text { standards and social practices, not just } \\
\text { affecting the systems' exchange potential } \\
\text { but also inducing path dependency. }\end{array}$ & $\begin{array}{l}\text { The investment that public authorities make in } \\
\text { non-renewable fuels infrastructure determines the } \\
\text { paths of future energy investments, locking into } \\
\text { some alternatives based on decisions made in } \\
\text { the past. }\end{array}$ \\
\hline
\end{tabular}

Source: Developed by the authors with insights from [37].

\subsection{Ecosystem Theory as an Approach to Study Industrial Symbiosis}

Ecosystem theory is showing increasing relevance in the academic community and providing evidence of its benefits $[2,4,38]$, through five main contributions to the scientific literature: 1 . it analyses organic networks, presenting not only their positive properties but also the negative ones: trophic competition, depredation, parasitism and destruction of the ecosystem. 2. It recognizes the actors' 
diversity with their own attributes, motivations and objectives, which determine the rationality of the decisions they make. 3. It frames the rational boundaries of the ecosystem on product/service supply chains, 4 . The dynamic evolution of ecosystems is required across time. 5 . The identification of behavioural and decisional patterns, which have an influence on the sustainability or decline of the ecosystem itself.

Ecology defines an ecosystem as "a community of living organisms whose vital processes are related to each other and are developed according to the physical factors of their environment." In a broad sense, we use ecosystem as a metaphor in the social sciences referring to system complexity [2]. Since the beginning of the conceptualization of IE as a scientific discipline $[1,21,39,40]$, the concept of a systemic relationship with the biosphere, has established a metaphor with the ecological ecosystem dynamics in which firms are considered as organisms exchanging material and energy between themselves and the environment. In this metaphor, the industry is seen as a semi-closed ecosystem where material and energy flows should be reincorporated in the system by a circular logic. However, it does not mean that inter-firm actions do not concern individual firms. On the contrary, individual firms must integrate IE in the individual project of each company to allow the embeddedness of the members of the system. Some examples of actions to integrate IE in the firm's project are the identification of resource flows (input/output) accountancy, the identification of synergy opportunities and the adoption of the system understanding. We can assume that the industrial ecosystem is not only a concept but also a project of social complexity integration with the aim to achieve sustainability.

Ecosystems can also be conceptualized from a business perspective, highlighting certain tensions present in industrial symbiosis, such as authority/autonomy, efficiency/resilience, cooperation/competition, global/local, among others [25]. Stakeholders cannot be conceived in a static way, since the network of interactions changes permanently and the purpose of ecosystem conceptualization is to demonstrate the mechanisms of dynamic change [25]. When the ecosystem is handled strategically [4], stakeholders are able to trade off the imbalances with their environment towards a stabilized dynamism, therefore a systematic analysis must be incorporated into the diagnosis, encompassing cause and effect relationships (cost reduction, productivity, efficiency, etc.).

\section{Methodology}

System dynamics is a methodology developed for the study of complex non-linear problems emanating from systems behaviour, able to incorporate, remove or change the structural mechanisms between actors and their idle periods. The publication of books like Industrial Dynamics [41], Urban Dynamics [42] and Limits to growth [43] gave birth to a tradition in the use of system dynamics to study complex issues, incorporating concepts such as retroactive flows and stock variables to the academic research on social systems within an evolutionary framework approach [41]. According to Forrester, J. [42] four features characterize system dynamics when modelling behaviour: 1. a boundary is drawn around the system, 2. retroaction generates ties of structural elements within the boundaries, 3. level variables represent accumulations within the feedback, 4 . velocity variables (flow) represent the activity within flows streams.

The Causal Loop Diagram (CLD) developed in this paper for the Dunkirk industrial symbiosis, introduces the concept of feedback loops for key social drivers. A geographical proximity perspective needs to be integrated into the system dynamics approach to cope with behaviour patterns, stakeholder's causal relationships, resources allocation decisions and environmental thresholds which influence future decisions, shaping the social industrial system depicted in the CLD. The system dynamics method addresses complex issues depicting the consequences of stakeholder's behaviours and agreements that may seem counterintuitive in the model. For example, the disruption of one loop like "private resources for innovation" can result in a reinforcing effect (positive polarity) in the "Emerging technology variable" or a balancing effect (negative polarity) in "Eco-efficiency technology" which counteracts or resists the direction of the original flow. The data used in this paper comes from primary and secondary sources. The secondary sources of information include the entire set of 
scientific papers and reports published in English and French regarding the industrial symbiosis from 1990 to now, gathering different perspectives and addressing different research questions. Besides, as primary sources engaged in this study, we include a set of interviews conducted with expert analysts and researchers that are involved in the organizational process and know in detail the local industry to corroborate the information obtained in the literature.

CLD's are an intermediary step between system conceptualization and the development of a quantitative simulation model. CLD 's may be used as an analytical tool in their own right. In this respect, this study does not extend to a numerical assessment of geographical industrial ecosystems, thereby excluding the model test and simulation of scenarios in qualitative terms; instead, it focuses on problem identification, identification of behavioural patterns and policy design and testing. Once the model is developed and the necessary data gathered, the next rational step in the analysis would be the integration of quantitative assessments to test the validity of the models through simulations.

For the case study, we used data from publicly available sources, interviews, site visits and collaborations with local organizations. Publicly available sources consist of 17 academic papers and reports in English and in French about the Dunkirk industrial symbiosis experience, encompassing different perspectives and addressing different questions. We then cross-validated the publicly available data obtained from the literature analysis presented in the Annex 1 Materials by interviewing some consultants who have repeatedly met with stakeholder of the industrial symbiosis.

The geographical system dynamics approach composed by three previously mentioned theoretical sources: complexity theory, stakeholder theory and ecosystems theory. It is important to provide theoretical foundations for a methodology which, from the best of our knowledge, has never been used in previous research studies, in order to give clarity to the arguments supporting this methodological choice. The geographical system dynamics method tries to integrate the differences while identifying the common features, to ensure their ability to represent territorial mental models, thus one of the main contributions of CLDs is the identification of key drivers able to cause large-scale changes in the system from small adjustments, a kind of multiplier effect. Even when parallel visions coexist in the understanding of the industrial ecosystem in Dunkirk, the coincidences' identification could contribute to draw up agreements and collective trajectories; therefore, system analysis gives access to structural and long-term simulations of the public policy interventions. The causal variables showed in the CLD offer two categories: 1 . The industrial by-product valorisation, and, 2 . The pooling of services as innovative strategy in the industrial symbiosis. The previous differentiation follows purposes, seeking to provide clarity to the loops but interlinkages are present in the full diagram depicted in Section 4.1. We designate variable titles by quotation marks in the text. In CLDs, the arrows indicate the causal relationships between the variables. These relationships can have a positive or negative sign. A positive sign implies that variable $X$ connects with variable $Y$ and they move in the same direction (an increase in $X$ leads to an increase in $Y$ and a decrease in $X$ leads to a decrease in $Y$ ). A negative relationship implies that the variables move in opposite directions (an increase in $X$ leads to a reduction in $\mathrm{Y}$ and a reduction in $\mathrm{X}$ leads to an increase in $\mathrm{Y}$. The feedback can both reinforce and balance (marked as $\mathrm{R}$ and $\mathrm{B}$ in the diagram).

\section{Results}

\subsection{The Dynamics Governing Industrial Symbiosis at Dunkirk}

Dunkirk is located in the north of France. With 88,000 inhabitants in 2016, it is the fifth most populated town in the "Hauts-de-France" region. The Dunkirk urban area has grown in a context of rapid territorial industrialization starting in the early 1990s, spurring port activity and the iron and steel industry through bilateral relations between firms which established the core for some early synergies related to waste recycling and energy flows. Since the 1960s, the industrialization of Dunkirk has had environmental consequences, especially atmospheric pollution, which in addition to the economic crisis in the 1990s lead to compelling requests to improve quality of life and environmental 
regulation. To meet this request, a shared territorial action plan emerged, paving the way for industrial symbiosis implementation, motivated mainly by industrial environment awareness [24].

Increasing conflicts between firms, local residents and environmental protection organizations persuaded local authorities to take part in conflict management and to seek agreements based on the recognition of diverse values regarding the environment [24]. The association of Economy and Ecology Partners in Local Action (ECOPAL in French), was created in 2001 as the local institution in charge of industrial ecology promotion in the territory and encouraging industrial symbiosis in Dunkirk through pooling services assistance. By-product synergies in Dunkirk industrial symbiosis also play a relevant role as depicted in Figure 2, which shows the by-product synergy network in 2018, composed by 14 firms that exchange by-products like scrap, steel slag, refractory bricks, steel mill dust, acid waste, tires, solvents, animal feed and used oil.

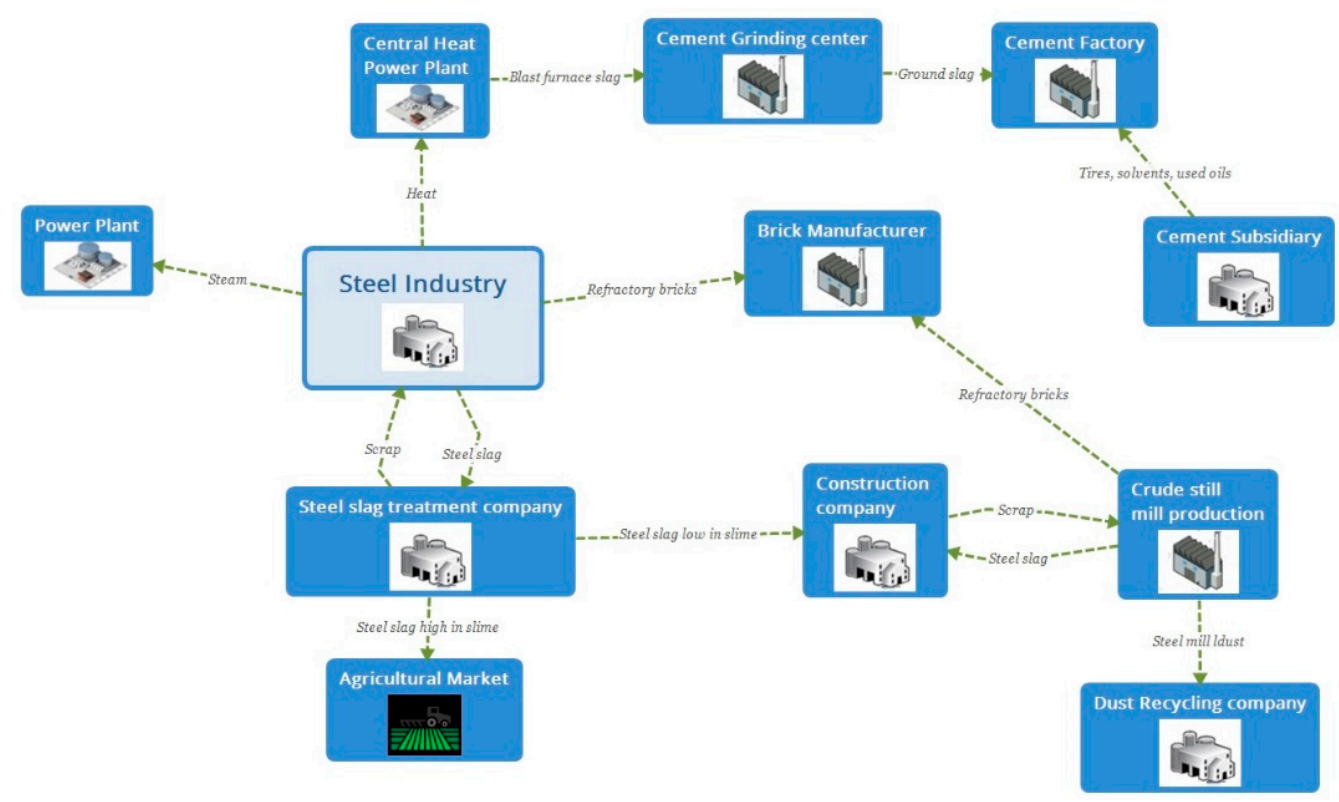

Figure 2. Dunkirk industrial symbiosis network schema. Source: Modified from [27] and translated to English by authors.

\subsection{Drivers for Industrial By-Product Valorization in Dunkirk}

We have identified "Industrial by-product valorisation" and "Pooling services" as key drivers in the emergence and endurance of industrial symbiosis, thereby influencing territorial embeddedness. The shift from the traditional individual firm logic into a system dynamics analysis implies structural changes in several areas, such as managerial practices, innovation strategies, local policies and the understanding of what used to be economic and political externalities. We start our analysis based on the assumption, derived from the chosen theoretical framework, which establish that the larger the "shift to an industrial symbiosis structure," the higher the "network resilience," encompassing political, economic, cultural and production values. We also identify three reinforcing feedbacks helping the "Industrial by-product valorisation": 1 . The less the amount of "Raw materials, energy, transport and landfill expenses," the less "Production costs," reflecting the integration of a by-product integration process through synergetic energy/material exchanges in the industrial ecosystem. Different underlying factors explain this proposed relationship, for instance social cohesion (political support increases when social cohesion increases) and environmental benefits (political support increases with environmental benefits). Savings from industrial by-product valorisation and income from the by-product sales improve the industrial performance in the symbiotic network. 2. Similarly, more "Network resilience" and "Cooperation proximity," spur cooperation within the organizational and institutional structures which has a positive impact on "Trustworthiness." The higher the 
professional and business confidence in the network, the higher the potential "Collaboration in contracts," thereby supporting the "Industrial by-product valorisation" (reinforcing feedback, R1-R2, Figure 3). 3. The higher the "Industrial by-product valorisation" the higher the "Network resilience," providing diversity in the resource supply and origin, including a local inter-connected exchange network to provide resilience through a diversity of by-product producers and users and accessibility to by-product producers and users in the industrial network (reinforcing feedback R3, Figure 3).

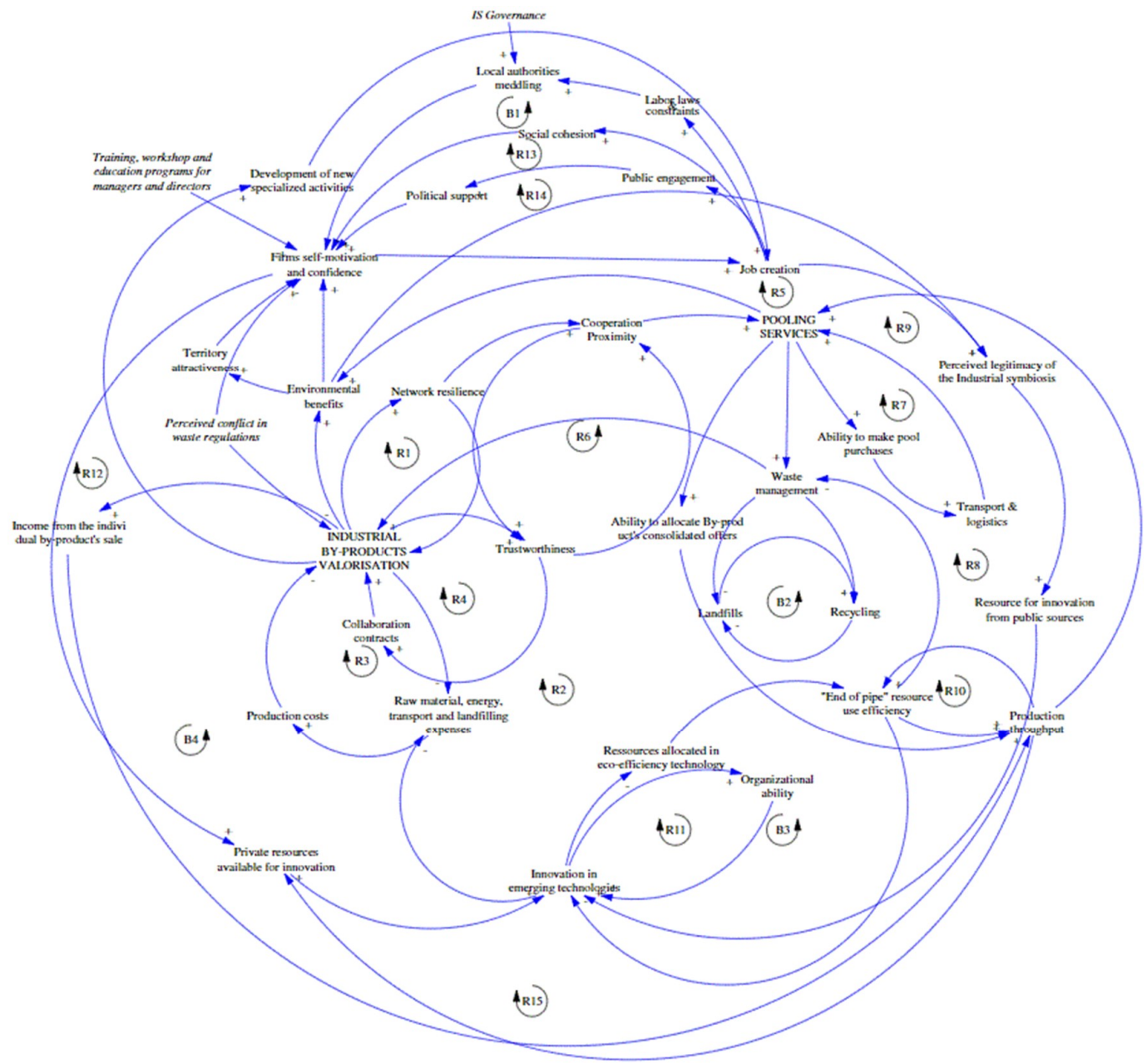

Figure 3. Causal Loop Diagram (CLD) depicting feedback processes in Dunkirk industrial symbiosis. Variables in capital letters represent key drivers in the emergence and endurance of the industrial symbiosis. Variables in italics denote proposed interventions.

\subsection{Hindrances to a Systemic Understanding of the Dunkirk Industrial Symbiosis}

We have identified two reinforcing feedbacks that counteract the move to industrial by-product valorisation: 1. When "Trustworthiness" is low in the network, the "Cooperation contracts" are also low, which hampers the development of industrial by-product valorisation in the industrial symbiosis (reinforcing feedback, R4, Figure 3), 2. Security of employment conditions and prosperity are fundamental for the territorial legitimacy of the industrial symbiosis. The higher the "Job conditions," the higher "The perceived legitimacy of the industrial symbiosis," obtaining legitimacy from political leaders results in the involvement of local and national authorities in order to supply more "Resources for innovation from public sources," which leads to an increase in the allocation of resources for "Innovation in emerging technologies." The more innovation in emerging technologies for by-product valorisation in the industry, the bigger the reduction in "Production costs," influencing "Industrial by-product valorisation" and in consequence fostering "Development of new specialized activities." 
The development of new work activities and needs from the network synergies has a positive effect on jobs in the territory (reinforcing feedback, R5, Figure 3).

In addition, there are two lock-in effects created by feedbacks linked to industrial symbiosis' current structure, which have an impact on the likelihood of a change in the industrial by-product valorisation: 1. Currently "Job creation" has a high impact on "Labour and law constraints." The labour regulations influence "Local authorities meddling" which increases the stringency of local and national authorities about the labour regulatory interventions, discouraging "Firms self-motivation and confidence." The less firms are self-motivated and confident in the industrial symbiosis, the less propensity to "Job creation" (balancing feedback, B1, Figure 3). 2. As "Recycling" increases, the waste sent to "Landfills" decreases, so encouraging recycling in the industrial symbiosis weakens the network's capability to transform waste into further by-products for exchange in the symbiosis (balancing feedback, B2, Figure 3). According to the reviewed literature [12,15-17,24,26-29], because symbioses are highly dependent on "Trustworthiness" in the relationship between directors and managers, a misunderstanding between them could mean a rupture in the "Cooperation proximity" influencing the synergy exchange between firms (reinforcing feedback, R6, Figure 3) due to the ancillary status of this by-product activity.

\subsection{Drivers of Pooling Services Innovation in the Dunkirk Industrial Symbiosis}

We have identified two relevant change processes regarding the Pooling Services potential in the industrial symbiosis: 1 . The transport and logistics expenses are a key part of the final production cost, 2. The potential agreements on pooled services in the industrial network spur production throughput. The encouragement of pooling services in the industrial symbiosis depends on the "Ability to make pool purchases," which leads to higher "Transport and logistics" benefits. An additional factor identified as important in this respect is the "Ability to allocate consolidated by-product offers." The more consolidated by-product stocks, the higher the production throughput even if it is outside the industrial symbiosis structure, joining the by-product market rationality (reinforcing feedbacks, R7-R8, Figure 3).

The "Territorial attractiveness" shapes the emergence of industrial symbiosis strategies, which is highly dependent on "Firms self-motivation and confidence." The more confidence and stability in the economic structure, the larger the "Job creation," in turn leading to a higher "Perceived legitimacy of the industrial symbiosis." The more "Resources for innovation from public sources" based on a better social perception of the legitimacy of the industrial symbiosis, the more "Innovation in emerging technologies," which leads to a higher public resource allocation, spurring "Production cost" reduction (reinforcing feedback, R9, Figure 3).

There is a struggle between allocating resources to existing "End of pipe resource use efficiency" technology or investing in "Innovation in emerging technologies." "Innovation in emerging technologies" means a new form of technology which influences the supply chain in a broader way, not just in the internal production of firms (e.g., raw materials, inputs and energy supplies, transport and logistics and landfill expenses). The higher "End of pipe resources use efficiency," the higher "Production throughput" of already existing eco-efficiency technology in the Dunkirk industries (reinforcing feedback, R10, Figure 3). The balancing feedbacks B3 and B4 (Figure 3) represent the fact that resources are limited and that the more resources are allocated either to innovation in emerging technologies or to strengthening current end of pipe eco-efficiency innovation, the less remains to spend elsewhere. The higher "End of pipe resource use efficiency" the lower the available inputs for "Waste management," which in turn means less available inflows for "Industrial by-product valorisation." A decrease in the industrial by-product valorisation entails a decrease in "Income from the individual by-products sale," so a negative influence on "production throughput" occurs. The choice of allocating resources to emerging technologies depends on "Organizational ability," which means the ability of the industrial network and external stakeholders to innovate when facing pressure. The higher "Organizational ability," the bigger the tendency to allocate resources towards new innovation areas. 
Counteracting such development is a reinforcing feedback which works through the "Raw materials, energy, transport and landfill expenses" (reinforcing feedback, R11, Figure 3).

"Firms self-motivation and confidence" depends on "Social cohesion," as well as "Political support" and "Environmental benefits." Three feedbacks reinforce the increase in "Firms self-motivation and confidence" in the industrial symbiosis at Dunkirk. First, "Income from individual by-product sales" facilitates "Innovation in emerging technologies," which paves the way for cost production optimization beyond the limits of internal productive processes by reducing "Raw material, energy, transport and landfills expenses," which in turn generates a reduction in "Production costs." Cost reduction strengthens the occurrence of "Industrial by-products valorisation" strategies. It also allows "Network resilience" through interactive and learning effects of production processes. Thus, "Cooperation proximity" helps the increase in "Pooling services," further supporting Environmental benefits" (reinforcing feedback, R12, Figure 3).

Another reinforcing feedback is the job creation loop. As "Firms self-motivation and confidence" happens in the industrial system, the stability in the social system boosts economic activity, which in turn creates more job opportunities in the territory, for example through the need to hire specialists in industrial ecology related activities. With higher "Job creation," "Social cohesion" gives attractiveness, encouraging higher "Firms self-motivation and confidence" (reinforcing feedback, R13, Figure 3). We have identified a conflict in waste regulation which is one of the main hindrances in the emergence and sustainability of the industrial symbiosis at Dunkirk. When "Firms self-motivation and confidence" occurs in the industrial symbiosis, it has the potential to increase "Job creation" which in turn generates "Public engagement," facilitating "Political support" and further supporting stakeholder self-motivation and confidence in the cooperation structure (reinforcing feedback, R14, Figure 3).

High "Production costs" in substitution synergies and pooling services are hindering factors in the industrial symbiosis evolution. Lastly, the larger "Industrial by-product valorisation," the higher the "Income from individual by-products sales," driving the industrial ecosystem towards an increase in "Production throughput." The higher the throughput derived from by-product valorisation, the higher the "Private resources available for innovation," leading to "Innovation in emerging technologies," which provides further benefits for the firms by the reduction of "Raw material, energy, transport and landfill expenses."

\subsection{Proposed Leverage Points and Interventions}

The proposed interventions in the symbiosis (Figure 3-variables in italics) target three different leverage points: "Training, workshop and education programs for managers and directors," "Industrial symbiosis Governance," "Perceived conflicts in waste regulations." The intervention proposed to increase "Firms self-motivation and confidence" is to implement "Training, workshop and education programs for managers and directors." This would increase the ability to undertake industrial symbiosis strategies in the industrial ecosystem, directly strengthening the reinforcing feedbacks R1, R2 and R3 (Figure 1). The "Perceived conflicts in waste regulations" weakens the overall ability to cope with uncertainty in the industrial network and is expected to weaken the reinforcing feedback R5 (Figure 1). Taken together, these developments could support the evolution of industrial symbiosis strategies. An intervention is proposed to increase the "Resources for innovation from public sources" to ensure "Innovation in emerging technologies," thereby creating "Raw material, energy, transport and landfilling expenses" reduction in the industrial symbiosis, as well as a higher potential for the emergence of "Pool services." The proposal to increase levels of "Industrial by-products valorisation" as a value-added step before thinking about "Recycling" aims to improve "Waste management." The proposal to facilitate "Development of new specialized activities" is targeting the fourth driver, "Job creation." By these means, spurring the local industrial ecosystem could gain social legitimacy for industry and address social challenges such as inequality, unemployment and health problems caused by pollution and so contribute to increase "Public support" and political support for the industrial symbiosis strategy. 
Political support, in turn, is partly dependent on public perception. "Perceived legitimacy of industrial symbiosis" increases "Public support" but this depends on the ability of the industrial ecosystem to provide environmental benefits (including air and water quality enhancement and reducing the amount of solid wastes send to landfills) and improving labour conditions and providing new job opportunities.

\section{Discussion}

The explanatory pathways leading to industrial symbiosis in Dunkirk can be explored through a geographical proximity analysis, using the six geographical dimensions [37] shaped by the CLD analysis (Table 2). In the Dunkirk industrial ecosystem, proposed interventions rank relatively high according to the literature reviewed and the experts interviewed. Some of the recurrent obstacles that the Dunkirk industrial symbiosis needs to tackle to achieve sustainability include technical, economic, informational, organizational, infrastructural and legislative problems [44,45].

Table 2. Geographical proximity analysis of the Dunkirk Industrial symbiosis systemic structure.

\begin{tabular}{|c|c|}
\hline Geographic Dimension & Dunkirk Industrial Symbiosis \\
\hline \multirow{2}{*}{ Location } & Absolute: Short distances in most synergy exchanges \\
\hline & Relative: Increase of proximity between the industrial park and the town \\
\hline Landscape & Potential problems regarding public acceptance \\
\hline & High decentralization of actors during by-product valorisation and consumption \\
\hline Territoriality & $\begin{array}{l}\text { High contiguity of by-product consumers and pooling services industries (local } \\
\text { industrial ecosystem) }\end{array}$ \\
\hline Scaling & Local/regional by-product valorisation and recycling \\
\hline $\begin{array}{l}\text { Spatial differentiation and } \\
\text { uneven development }\end{array}$ & Re-working of local and regional core/periphery patterns \\
\hline & Lock-in of waste regulations and standards. \\
\hline $\begin{array}{l}\text { Spatial embeddedness and } \\
\text { path dependency }\end{array}$ & $\begin{array}{l}\text { Path dependencies due to an existing eco-efficiency expertise and networks } \\
\text { between industrial managers and local authorities. }\end{array}$ \\
\hline
\end{tabular}

Industrial ecology analyses social relationships, characterized by irreversible and dissipative flows in time and space, this circular understanding of systems is consistent with our understanding of industrial symbiosis, open dynamic systems [42], stakeholder theory [46] and complex adaptive theory [47]. Therefore, industrial symbiosis as a social innovative strategy embedded in Industrial ecology should be able to inspire the sustainability paradigm shift in industry at the local scale [48]. In this study, we frame the socio-economic approach with the theoretical assumption that position dialectic logic at the heart of industrial symbiosis's sustainability [36]: cooperation/competition, efficiency/resilience, local/global and autonomy/authority, coming from a coherent theoretical framework. In addition, other relevant insights stress the centralized/de-centralized governance in the symbiosis dynamic: anchor-tenant relationship or scavengers' symbiosis dynamic [7,18].

Location: the territorial scale produces institutions' representations referring to social structures according to our models. At the local level (microsocial), the governance mechanisms are decided and applied by social actors, who at the same time are regulated by those same mechanisms [49]. This analysis shows that lack of communication within stakeholders represents one of the main hindrances to the industrial symbiosis, even when the Absolute geographical location that separates the actors is short. The symbiosis takes place within a perimeter of $17 \mathrm{~km}$ around the industrial zone, along the coast boarder, starting from the town of Saint Georges sur l'Aa to the port of Dunkirk [50], with an average distance of $2-3 \mathrm{~km}$ between collaborative firms. From the Relative location perspective, the collaboration principle acts on the inter-firm relationships (network members) encouraging them to extend their boundaries thanks to the communication and transport investment in the search for external partner integration (suppliers, customers, municipality, etc.). Industrial symbiosis implementation is determined by several factors, such as the nature of the activities, the history, 
location, coordination willingness and the existing organizational structure of industrial symbiosis stakeholders [51].

Landscape: The Dunkirk industrial symbiosis is based on electricity, steelmaking slag, heat, scrap, acid waste, refractory brick exchanges and pooling services coordinated by ECOPAL. Electricity production through a residual steam and public heating network have public acceptance, however the increase in steelmaking slag and scrap and increases in wastewater and sewage sludge could face legitimacy problems with regard to the environmental impacts of these activities in the territory. Large-scale infrastructure interventions are likely to cause protests, because of the negative public image of disposal problems. In the industrial symbiosis, the potential scale-up of the public urban heating network might result in landscape changes in the town, due to the industrial strip that surrounds the city, triggering competition with other forms of land use.

Territoriality: The territory of the Dunkirk IS has a decentralized structure (low centralization), as the valorisation of by-product is individually handled by the firms, which produce each by-product independently. The industrial by-product valorisation entails relatively low connectivity and high contiguity, because firms exchange by-products locally. The municipality of Dunkirk is involved in the public heating network and the sewage treatment project, which increases connectivity while decreasing contiguity. Contiguity is high when the raw materials and inputs used in the production process come from the Dunkirk area and low when they are transported over long distances to be integrated into the production process. Industrial symbiosis is an organizational strategy, which fosters contiguity in the geographical dimension of the supply chain. Since the steel and construction industries are essential in the Dunkirk industrial ecosystem, both sectors have a big potential to be strategically embedded in the territory, closing supply and demand loops, supported by emerging technologies and investments as shown in the CLD (balancing feedback B3, Figure 3). The governance structure in Dunkirk encompasses very few stakeholders and is therefore dependent on a small and centralized set of by-products, triggering some structural problems because of the low ubiquity (understood as the number of firms that produce and consume each waste exchanged within the IS) and low diversity of by-products and the small number of firms that produce and consume.

Scaling: Industrial symbiosis is a multi-scale phenomenon-from the microscale of individual firms to the mesoscale of industrial ecosystems. When we talk about industrial ecosystems, we do not ignore the role played by the individual firms, on the contrary we attempt to stress the role of concepts like industrial symbiosis, that provide socially warranted meaning to individual actions, therefore defining how individual firms perceive problems and link them to the potential solutions. Some of the problems that need to be addressed collectively, if firms want to tackle them, are for example water source allocations, by-products synergies, environmental problems, employee qualifications and energy alternatives. At the same time, firms are also involved in global market dynamics, because their final products are usually sold in international markets. Thus, industrial symbiosis should be able to integrate global (large-scale cycles) and local (small-scale cycles), which in the long term is an attempt to balance geographic imbalances by closing global raw materials cycles imported at Dunkirk. This means that the Dunkirk IS seeks to reduce its outside dependence on raw materials and energy through the by-product valorisation and the by-product reincorporation in the industrial ecosystem cycles. From the perspective of the geographical system dynamics approach, we assume that the transitional de-globalization process, usually takes place in the Dunkirk IS case study, without causing shortage related problems (i.e., the transport of low economic value materials is unfeasible due to costs and carbon emissions) but providing an opportunity to supply inflow demand through locally produced by-products. These results cannot be generalized to other industrial symbiosis experiences with different geographical and social environments but it sheds light on an interesting topic that is rarely discussed in the academic Industrial ecology literature.

Spatial differentiation and uneven development: The spatial differentiation of the Dunkirk industrial symbiosis is closely related to location and scaling, since processes of convergence and differentiation find expression in proximities and economies of scale. Spatial differentiation [37] 
reveals the rework of established patterns, that is, Housing concentration is defined by industrial ecosystems, which provides job opportunities. Regarding uneven development, the current supply sources of the Dunkirk IS are geographically disparate, according to Dunkirk trade balance [52]. With big deficits in carbon oil, waste oil and other raw materials, while at the same time being a global provider of steel, construction, energy, agriculture machinery and inputs for the car and pharmaceutical manufacturing industries.

Spatial embeddedness and path dependency: The current eco-efficiency technology, which has a functional infrastructure to develop "end-of-pipe" solutions, influences and paves the way for the future political and institutional pathways to follow. The highly centralized technological investments and the few opportunities for emerging technologies, hinder the industrial by-product valorisation and the pooling services in the industrial symbiosis strategy. Implementing eco-efficiency strategies based on centralized systems therefore reproduces the lock-ins concerning the socio-ecological industrial ecosystem. Infrastructural decisions for the future induce the path dependencies in Dunkirk, including the political choices of new mono-incineration plants that influence the expected scenarios of the industrial ecosystem for stakeholders and decision-makers.

\section{Conclusions}

The conceptualization of governance in IS is not simple to understand and internalize because of the complexity involved in the ecosystem and the stakeholders' conflicts of interest. The success of the IS is mainly related to the governance quest which is the balance between the autonomy/authority, cooperation/competition strategies engaged through local/global scales. The governance [53] encompasses ecological, cultural, political and economic embeddedness of actors and the means of governance become crucial to enhance the self-organization. The territorial approach of industrial symbiosis encourage its emergence and sustainability, thus assuring redundancy for key functions. In this study, the functional understanding gains relevance in the Dunkirk industrial symbiosis, when analysing the causal loops through a complex adaptive method for social industrial ecosystems.

Systems analysis is a methodology which aims to improve the understanding of human motivational causality and the network interactions, including the economic and political contextual drivers in the industrial ecosystem, inquiring into stakeholders' behavioural patterns, conflicts of interests, values and motivations. In the literature review, academics define industrial symbiosis as a social innovation which goes beyond the positive scientific approach, we attempt to recognize its standardized dimension, referring to human intentionality and the aim of improving industry. If well steered, industrial symbiosis has the potential to improve innovation and resilience in industry, encouraging industrial ecosystem development, providing a scientific structure to deal with the social intentionality in a systemic way, based on the multiplicity of values, diversity of interests and stakeholder preferences. Looking to make a geographical analysis of industrial symbiosis with a theoretical framework, we draw up six geographical dimensions to improve the systemic understanding able to drive this approach towards a dynamic science [49].

There have been many structurally complex studies of industrial symbiosis at the micro-level but few equivalent studies at the micro- or meso-level looking at the behaviour of actors and its institutions, determined by the social private/public structure.

This study is not exempt from criticisms related to the research method in terms of robustness and validity; the ideas expressed by the experts during the interviews and gathered from the literature review are not directly transferable to industrial symbiosis. The comparability of results with other studies and the generalization of conclusions is debatable; however, the originality of this method can contribute to the understanding of the role of territory in the industrial symbiosis strategy in the search for sustainability. The originality of the geographic system dynamics is based on the richness of references and qualitative information collected, structured in a systemic and reproducible method. 
Author Contributions: Research design, methodology application and formal analysis, M.M., data analysis, resources, writing, review and editing M.M. and A.D, Project administration and funding acquisition A.D.

Funding: This research received specific grant from Erasmus+ Programme of the European Union and from the Jean Monnet Excellence Center on Sustainability (ERASME).

Acknowledgments: The authors wish to thank the Dunkirk Urban Land Development Agency (AGUR-Dunkerque) and the Arcelor's Mittal Sustainability Department for the great and very helpful insights they provided considering the practical experience they have in the field and to the anonymous reviewers for very helpful comments, insights and advice that greatly improved the paper.

Conflicts of Interest: We wish to confirm that there are no known conflict of interests associated with this publication. We confirm that the manuscript has been read and approved by all authors and we confirm that all of us approved the authorship order in the manuscript.

\section{References}

1. Frosch, R.A.; Gallopoulos, N.E. Strategies for Manufacturing. Sci. Am. 1989, 261, 144-152. [CrossRef]

2. Nielsen, S.N. What has modern ecosystem theory to offer to cleaner production, industrial ecology and society? The views of an ecologist. J. Clean. Prod. 2007, 15, 1639-1653. [CrossRef]

3. Hess, G. L'écosystème industriel. Difficulté épistémologique d'une telle analogie. Nat. Sci. Soc. 2009, 17, 40-48. [CrossRef]

4. Tsujimoto, M.; Kajikawa, Y.; Tomita, J.; Matsumoto, Y. A review of the ecosystem concept-Towards coherent ecosystem design. Technol. Forecast. Soc. Chang. 2018, 136, 49-58. [CrossRef]

5. Boons, F.; Spekkink, W.; Isenmann, R.; Baas, L.; Eklund, M.; Brullot, S. Comparing industrial symbiosis in Europe: Towards a conceptual framework and research methodology. In International Perspectives on Industrial Ecology; Edward Elgar: London, UK, 2015; pp. 69-88. [CrossRef]

6. Boons, F.; Spekkink, W.; Mouzakitis, Y. The dynamics of industrial symbiosis: A proposal for a conceptual framework based upon a comprehensive literature review. J. Clean. Prod. 2011, 19, 905-911. [CrossRef]

7. Chertow, M.R. Uncovering industrial Symbiosis. J. Industrial Ecol. 2007, 11, 11-30. [CrossRef]

8. Mirata, M. Experiences from early stages of a national industrial symbiosis programme in the UK: Determinants and coordination challenges. J. Clean. Prod. 2004, 12, 967-983. [CrossRef]

9. Walls, J.L.; Paquin, R.L. Organizational Perspectives of Industrial Symbiosis: A Review and Synthesis. Organ. Environ. 2015. [CrossRef]

10. Salmi, O. Eco-efficiency and industrial symbiosis-A counterfactual analysis of a mining community. J. Clean. Prod. 2007, 15, 1696-1705. [CrossRef]

11. Liu, Z.; Adams, M.; Cote, R.P.; Geng, Y.; Li, Y. Comparative study on the pathways of industrial parks towards sustainable development between China and Canada. Resour. Conserv. Recycl. 2018, 128, 417-425. [CrossRef]

12. Leurent, M.; Da Costa, P.; Sylvestre, S.; Berthélemy, M. Feasibility assessment of the use of steam sourced from nuclear plants for French factories considering spatial configuration. J. Clean. Prod. 2018, 189, 529-538. [CrossRef]

13. Diemer, A.; Labrune, S. L'écologie industrielle: Quand l'écosystème industriel devient un vecteur du développement durable. Développement Durable Territ. 2007, 1-26. [CrossRef]

14. Saavedra, Y.M.B.; Iritani, D.R.; Pavan, A.L.R.; Ometto, A.R. Theoretical contribution of industrial ecology to circular economy. J. Clean. Prod. 2018, 170, 1514-1522. [CrossRef]

15. Jedelhauser, M.; Binder, C.R. The spatial impact of socio-technical transitions-The case of phosphorus recycling as a pilot of the circular economy. J. Clean. Prod. 2018, 197, 856-869. [CrossRef]

16. Hampikian, Z. Structuration urbaine d'un réseau de chaleur et énergie fatale: La proximité comme variable dynamique. Flux 2017. [CrossRef]

17. Beaurain, C.; Varlet, D. Régulation des interactions au sein d'un réseau territorialisé d'entreprises dans le cadre de l'écologie industrielle. 2015. Available online: http://rei.revues.org/6262 (accessed on 10 December 2018).

18. Chertow, M.R. Industrial symbiosis: Literature and Taxonomy. Annu. Rev. Energy Environ. 2000, 25, 313-337. [CrossRef]

19. Buclet, N. Ecologie Industrielle et Territoriale: Stratégies locales pour un Développement Durable; Presses Universitaires du Septentrion: Villeneuve d'Ascq, France, 2011. 
20. Buclet, N. Essai d'écologie territoriale: l'exemple d'Assois en Savoie; CNRS: Paris, France, 2015.

21. Ayres, R.; Ayres, I. A Handbook of Industrial Ecology; Edward Elgar: Northampton, MA, USA, 2001.

22. Boiral, O. Concilier Environnement et competitivite, ou la quete de l'eco-efficience. Revue Francaise de Gestion 2005, 31, 165-186. [CrossRef]

23. Mayer, A.; Haas, W.; Wiedenhofer, D.; Krausmann, F.; Nuss, P.; Blengini, G. Measuring progress towards a Circular Economy: A monitoring framework for economy-wide material loop closing in the EU28. J. Ind. Ecol. 2019, 23, 62-76. [CrossRef]

24. Beaurain, C.; Brullot, S. L'écologie industrielle comme processus de développement territorial: Une lecture par proximité. Rev. D'economie Régionale Urbaine 2011, 2, 313-340. [CrossRef]

25. Freeman, R. Strategic Management: A Stakeholder Approach; Pitman Publishing: London, UK, 1984.

26. Hein, A.M.; Jankovic, M.; Feng, W.; Farel, R.; Yune, J.H.; Yannou, B. Stakeholder power in industrial symbioses: A stakeholder value network approach. J. Clean. Prod. 2017, 148, 923-933. [CrossRef]

27. Beaurain, C.; Varlet, D. Some tracks of reflection for a pragmatic approach of industrial ecology: The example of the urban area of Dunkirk. Rev. Développement durable et territoires 2014, 5, 1. [CrossRef]

28. Kasmi, F.; Laperche, B.; Merlin-Brogniart, C.; Burmeister, A. Écologie Industrielle, milieu Innovateur et Gouvernance Territorial; Le cas de Dunkerque: Dunkerque, France, 2017.

29. Boutillier, S.; Laperche, B.; Uzunidis, B. Rapport Le Territoire Entrepreneurial Durable: Etude du cas de Dunkerque (Nord-France); Institut CDC pour la Recherche: Paris, France, 2015.

30. Bennich, T.; Belyazid, S.; Kopainsky, B.; Diemer, A. The bio-based economy: Dynamics governing transition pathways in the Swedish forestry sector. Sustainability 2018, 10, 976. [CrossRef]

31. Ostrom, E.; Basurto, X. Crafting analytical tools to study institutional change. J. Inst. Econ. 2011, 7, 317-343. [CrossRef]

32. Morin, E. Le Paradigme perdu: La Nature Humaine; Editions du Seuil: Paris, France, 1973.

33. Morin, E. La Methode; Editorial du Seuil: Paris, France, 1977.

34. Morin, E. Introduction a la Pensée Complexée; Editorial du Seuil: Paris, France, 2005.

35. Patrucco, P.P. Collective knowledge production costs and the dynamics of technological systems. Econ. Innov. New Technol. 2009, 18, 296-310. [CrossRef]

36. Diemer, A.; Morales, M.E. rfdd-2016-HS4-Morales Diemer (1). Revue Francophone Du Développement Durable 2016, (Special issue 4), 52-71.

37. Bridge, G.; Bouzarovski, S.; Bradshaw, M.; Eyre, N. Geographies of energy transition: Space, place and the low-carbon economy. Energy Policy 2013, 53, 31-340. [CrossRef]

38. Morales, E.M.; Diemer, A.; Cervantes, G.; Carrillo-González, G. By-product synergy" changes in the industrial symbiosis dynamics at the Altamira-Tampico industrial corridor: 20 Years of industrial ecology in Mexico. Resourc. Conserv. Recycl. 2019. [CrossRef]

39. Erkman, S. Vers une Ecologie Industrielle: Comment Mettre en Pratique le Développement durable dans une Société Hyper-Industrielle; Charles Léopold Mayer: Paris, France, 2004.

40. Durlauf, S. Complexity and Empirical Economics. Econ. J. 2005, 115, 225-243. [CrossRef]

41. Forrester, J. Industrial Dynamics; MIT Press: Cambridge, MA, USA, 1961.

42. Forrester, J. Urban. Dynamics; MIT Press: Cambridge, MA, USA, 1970.

43. Meadows, D.; Meadow, D.; Randers, J.; Behrens, W., III. Limits to Growth; Potomac Associates-Universe: New York, NY, USA, 1972.

44. Duret, B. Premiers retours d'expériences en écologie industrielle: Études de cas en Europe et en Amérique du Nord; Cahiers de la Chaire d'écologie industrielle CREIDD, Université de Troyes: Troyes, France, 2005.

45. Association Orée. Recueil des démarches d'écologie industrielle et territorial; Département énergie et climat-ARENE-IAU îdF: Paris, France, 2013.

46. Freeman, R. The politics of Stakeholder Theory. Bus. Ethics Q. 1994, 4, 409-421. [CrossRef]

47. Passet, R. La Gestion des Ressources de la planète: L'approche Économique; Cahiers Français: Paris, France, 1991.

48. Metereau, R.; Figuière, C. Ecologie industrielle. Le secteur agroalimentaire comme point de départ pour une organisation écosystémique des activités humaines. In Ecologie Industrielle et Territorial; Dans, G.J., Brullot, S., Eds.; Presses des Mines: Paris, France, 2015; pp. 215-232.

49. Joubert, J.; Brullot, S. Etudes des dimensions sociales des démarches d'écologie industrielle et territorial. Quelle méthode pour quel type de résultats? In Ecologie Industrielle et Territorial; Dans, G.J., Brullot, S., Eds.; Presses des Mines: Paris, France, 2015; pp. 33-44. 
50. Dunkerque Promotion. Dunkerque Promotion: Agence de Promotion Economique. Available online: www.dunkerquepromotion.org (accessed on 22 December 2018).

51. Diemer, A. Qu'avons-nous appris des symbioses industrielles? In Ecologie Industrielle et Territorial; Dans, G.J., Brullot, S., Eds.; Presses des Mines: Paris, France, 2015; pp. 173-186.

52. Agence d'Urbanisme et Développement de la Région Flandres-Dunkerque. Retrieved from La Toile Industrielle de Dunkerque. Available online: http:/ / www.agur-dunkerque.org/etudes-projets/article13 (accessed on 22 November 2018).

53. Boons, F.; Baas, L. Industrial symbiosis in a social science perspective. In Proceedings of the Discussion Proposals for the Third Industrial Symbiosis Research Symposium 2006, Birmingham, UK, 5-6 August 2006.

(C) 2019 by the authors. Licensee MDPI, Basel, Switzerland. This article is an open access article distributed under the terms and conditions of the Creative Commons Attribution (CC BY) license (http://creativecommons.org/licenses/by/4.0/). 